\title{
A Novel Methodology for Improving Teaching Learning Process and its outcome on 2K Students for Engineering Education
}

\author{
K.Vasanth ${ }^{1}$, C.N.Ravi ${ }^{2}$, A.Padmaja ${ }^{3}$, M. Rajendra Prasad ${ }^{4}$ \\ ${ }^{1}$ Department of ECE, Vidya Jyothi Institute of Technology, Aziz Nagar, Chilukur Road, Hyderabad- 500075 \\ ${ }^{2}$ Department of EEE, Vidya Jyothi Institute of Technology, Aziz Nagar, Chilukur Road, Hyderabad- 500075 \\ ${ }^{3}$ Principal, Vidya Jyothi Institute of Technology, Aziz Nagar, Chilukur Road, Hyderabad- 500075 \\ ${ }^{4}$ Department of ECE, Vidya Jyothi Institute of Technology, Aziz Nagar, Chilukur Road, Hyderabad- 500075 \\ ${ }^{1}$ vkbece@vjit.ac.in \\ ${ }^{2}$ ravicn@vjit.ac.in \\ ${ }^{3}$ principalvjit@vjit.ac.in \\ ${ }^{4}$ rajendraprasad@vjit.ac.in
}

\begin{abstract}
Over the years, various teaching methodologies such as socio constructive perspective, group projects, Mind Map, Z to A approach, Role play, Brown Bag were used to deliver engineering education easily to students so that they retain the concepts well. This paper deals with an effective teaching methodology named "Never Miss a Class" designed for $2 \mathrm{~K}$ engineering students. The Method uses a video prepared by the instructor that briefs the content that happened in the class. If a student is absent for the concerned class then the instructor uploads the video to the students broadcast group on their personal phone (namely Whats app Group). The advantage of this technique is that even if the student misses the class, the video will be available with him at any time for learning. This is effective for numerical based papers in Engineering. The proposed teaching methodology is implemented on the second and third year students of Electronics and Communication Engineering of Vidya Jyothi institute of technology, Hyderabad. The effectiveness of the proposed technique is vivid when compared with other conventional teaching methodologies, when the former has good end exam results and the concept retaining capability of the students, when compared to latter. A proposed teaching methodology surpasses other methods thereby enabling the students to reproduce the concepts during their semester exam, or questioned elsewhere.
\end{abstract}

Keywords: Innovative teaching practices; Outcome based education; Learner centric approach

\section{Corresponding Author \\ K.Vasanth, Department of ECE, Vidya Jyothi Institute of Technology, Aziz Nagar, Chilukur Road, Hyderabad- 75 vkbece@vjit.ac.in}

\section{Introduction}

The role of a teacher in a class room is to gainfully engage the students in a full quota of the classwork assigned to him. The word gainfully becomes trivial if the subject is a little difficult to understand. Most of the engineering subjects are difficult to understand as the subjects taught are mere maths or explained as just theory. The main hurdle of the teacher to teach engineering subjects is to create a virtual environment in the mind of students and visualize the concept in their understandable world. This makes it easy for the students when they prepare themselves for the outside world in terms of interview or viva voce. The lack of innovation in teaching has resulted in a copy routine practice for students in completing any of the given tasks in the form of Homework or assignments or seminars. The wide use of Information and Communication Technology (ICT) based methods lack the conventional approach (black board chalk) in elaborating the concepts with a few more examples. Wald [1] gave the trends in engineering education using internet and group projects. Different learning strategies were discussed for effective transfer of knowledge to the learner by Schunk [2]. Mcmohan [3] discussed the use of socio constructivism on World Wide Web. The essence of collaborative learning and its impact on social psychology is discussed in work of Johnson et al [4]. The effect of student teams and its impact on class room education is illustrated by DeVries et al [5]. Cohen gave different instructional methods and strategies for Heterogeneous class rooms [6]. Rajendra Prasad et al [7] introduced project based learning, its role on engineering curriculum and its impact on students understanding. Woods [8] introduced problem based learning and its impact on students concept understanding. 
Springer et al [9] proposed the impact of small group learning on science and technology. Docy et al [10] deals with the effect of problem based learning imparted on learner centric approach. The students who are born after the year 2000 are exposed to videos through the freely available internet in the form of videos. These students lack interest in conventional class room teaching. Hence suitable methodologies are to be formulated with a good teaching and learning model that enhances learning experience to the students. Section 2 deals with the different innovative teaching methodologies adopted to make engineering education easy. Section 3 gives the outcome of the innovative teaching methodology adopted. Section 4 gives the conclusion of the paper.

\section{Innovative Teaching Methodologies}

Few innovations in teaching and learning are used by the department. These innovative teaching methodologies are followed to give Clarity in learning for the students on engineering subjects. The innovative teaching methodologies are introduced by senior faculty members (10 years experience) in front of Department Academic Committee/Counsel (DAC). In turn, the methodologies are amended based on their merits by the DAC member. Later, the methodology is briefed to the faculty members and are insisted on following the same. The faculty members prepare their lesson plan by planning a few topics to be taught using innovative teaching methods demonstrated in the department. The main mottos of the methods are to give clarity in engineering education. These techniques are framed keeping in view easy engineering education to the students so that the students can easily adapt to changing industrial requirements. The different types of innovative teaching methodologies used in the department are

- Socio constructive perspective [3]

- Group projects [1],[7]

- $\quad$ Mind Map

- Z to A approach

- Dramatic technical Role play

- Brown bag

- Never miss a class approach

Let us see how these techniques are implemented, evaluated, and how outcome is obtained using each of them.

\section{A. Socio Constructive Perspective}

In a conventional class, there is always a thin line between subject learnt by understanding and getting acknowledgement from the student (McMahon, 1997). This is often clarified with the social world. In this technique social world knowledge is disseminated to students appropriately and that transforms students to acknowledge a concept. This kind of a technique is an active process. Hence, the student listens to the social context and understand concept as shown in figure 1 .

IDEA: In this technique, a video/ animation is played on selected topics of Electronics and communication engineering subject.
IMPLEMENTATION: A set of questions posted by the evaluator / teacher/ professor for the students on the played video/ animation at random.

EVALUATION \& OUTCOME: Questions from the played video are posted to students randomly. It was found that most of the students of the class were at ease in answering the questions. The methodology was adopted for a subject who requires intuition to understand the concepts of the subjects such as Microwave engineering, Signals and systems, Fabrication of VLSI IC, Linear IC applications, Antenna and Wave Propagation. It was significant to see the acknowledgement from students even at the fag end of the day.

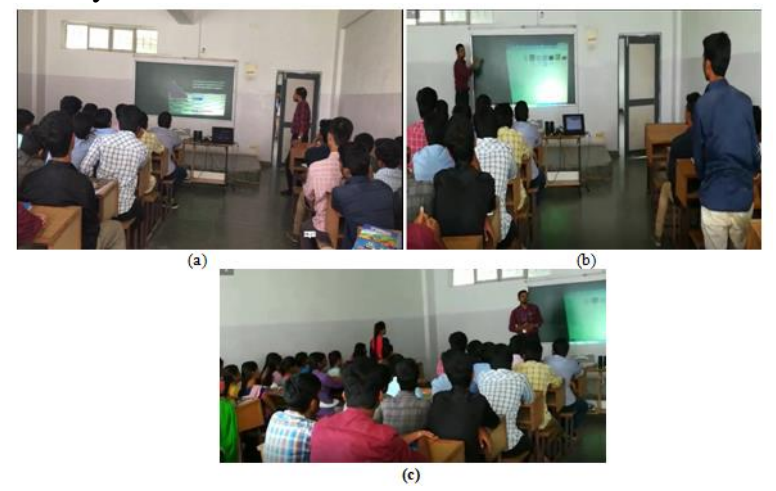

Figure 1 (a) Animation video is played on a topic (b)-(c) Students was evaluated by asking questions to students randomly.

\subsection{Group Projects}

A group of interested students who have zeal to explore technical concepts are made to understand the concepts of advanced topics by choosing a common IEEE/SPRINGER/ ELSEIVER published research paper or any topic that is taught only as part of theory. Students are divided into 4 in a group and made to implement one single research paper by assigning different roles. Basic subjects that requires higher understanding is made easy by a single group projects done by a set of students as shown in figure 2 .

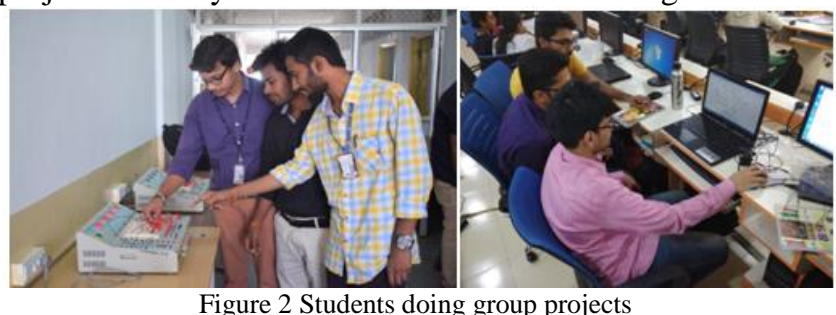

IDEA: To make students understand IEEE/ Springer /

Elsevier research papers and implements a part of it by a set of interested students.

IMPLEMENTATION: Students are taught with software or given hands on approach with existing hardware to build or get the output of a desired paper.

EVALUATION \& OUTCOME: Evaluation is done by making students implement the concept studied from a common paper in different forms using their creativity. These techniques were introduced in the course called switching theory and logic design (STLD), Electronic Devices and circuits (EDC), Linear Digital IC applications, Image processing. It was observed that the understanding level of students were higher when compared to other teaching methods. 


\section{Mind Map}

This technique as shown in figure 3 is used at the end of a Unit in a course. This technique will help the students to relate the concepts from which it is derived. Hence this technique is apt, if is used where hierarchical approach of concepts are to be correlated. These concepts were implemented in Semiconductor devices in a course called Electronics Devices and Circuits (EDC), Memories concept in the course called Computer Organization. This technique creates brainstorm for students. Hence, a general discussion proceeds thereafter.

IDEA: Faculty member prepares a set of slides that has hierarchical relation with one concept or at the end of a unit, students are asked to prepare a Mind Map on concepts related to that particular unit.

IMPLEMENTATION: A day before the activity is planned, students are requested to prepare a relational Map about the unit/topic discussed. Students are requested to make a colourful Map on an A3/A4 paper. The Next day students bring the self made Mind map to class. Students are picked at random to explain the Mind map made by them. Other students listen to the explanation and answer the points that are left out.

EVALUATION \& OUTCOME: Students' involvement in making their colourful Mind map with creativity and intuition is the best outcome. The Maps are made by students. Hence, a cumulative understanding about a particular concept is achieved by the students.

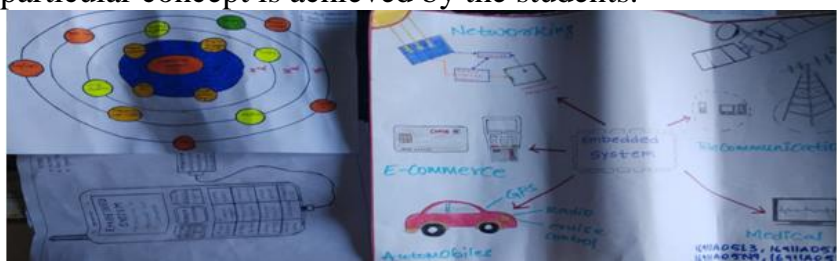

Figure 3 Snap shot of Mind map performed by students

\section{Z- A Approach}

This technique gives the applications or results obtained or effects of a topic followed by the concepts as shown in figure 4 . This technique can also be visualized as reverse engineering of learning process. This approach is used in Microprocessor and its interfacing, Electromagnetic wave theory, Antenna and wave propagation, Digital communication and embedded systems.

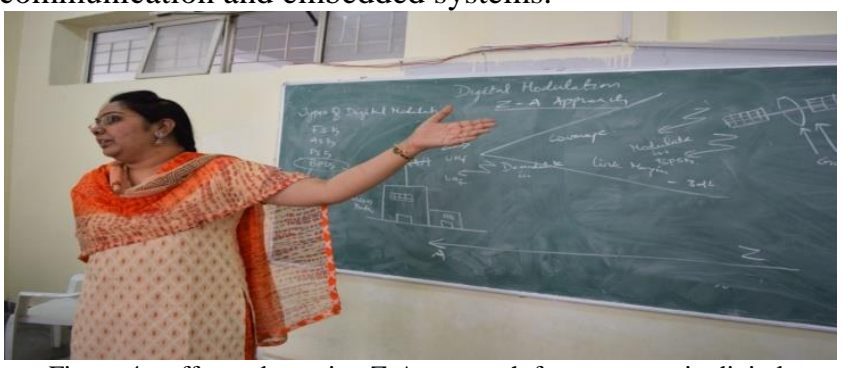

Figure 4 staff member using Z-A approach for a concept in digital communication

IDEA: Attempt to explain the application for a particular concept first and then the concept itself.

IMPLEMENTATION: Consider the course on microprocessor and interfacing, listing different peripherals (like keyboard, mouse, LEDs and switches) used for better operation of 8086 microprocessor based system design.
Hence, discussion of interfacing them with 8086 has to be explained. Initially the interfacing diagram and need of using 8255 for interfacing 8086 with peripherals by increasing the number of $\mathrm{I} / \mathrm{O}$ ports is discussed subsequently and the 8255 architecture is discussed later.

OUTCOME: Creating interest among the students in knowing the topic is the outcome. The interest showed by students when Z-A approach used by faculty has been good The involvement of students was phenomenal as they answer to the questions even before the topic has been taught. This enhances the learning capability of the students.

\section{E. DRAMATIC ROLE PLAY:}

In this method, a group of students is given a character, which is part of the concept that is to be taught in the class. This method will enable a student to understand the concept better as the role play follows a sequence of actions rather than learning, as shown in figure 5. The concept to be taught also follows a sequence. Hence, interactive enacting of concepts will enable students to acknowledge the concept far better than conventional instructional methods.

IDEA: A particular concept which is to be taught is planned by the faculty in advance. Group of students were given with a role in the concept that is to be taught. A sequence of events or screenplay is prepared.

IMPLEMENTATION: An example of sampling was taught for the course signals and systems using this technique. A group of students will act as analog signal and train of impulse; an individual will act as a Fourier operator. A screenplay of sequence of events is discussed below.

Sequence 1: First, the characters (operation) to be played in the sampling theorem are introduced.

Sequence 2: Applying the Fourier transform on the analog signal and train of impulse.

Sequence 3: Perform Multiplication of both the signals Sequence 4: Process of Reconstruction

Sequence 5: Under-sampling, Oversampling, Nyquist rate

EVALUATION \& OUTCOME: After the play students will narrate the sequence of events with example. Staff members will question some students at random and asks about the concepts of the topic played. This technique helps students in understanding the topic quickly without hassle. This method also suggests that the concepts can be with great level of acknowledgement when compared to conventional methods.

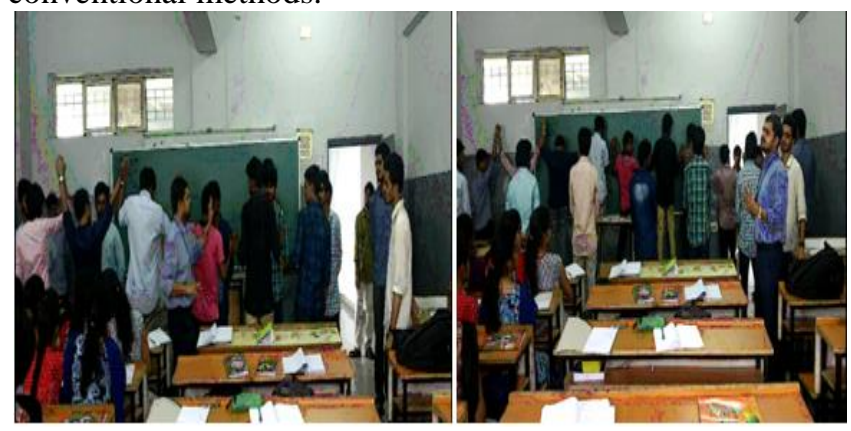

Figure 5 Screen shot of Dramatic role play followed by students interaction

\section{F. Brown bag approach}

This method is used to check the understanding capability of the student in a lecture. Initially for a 1 hour lecture the 
faculty member will take class for about 45 Minutes and the last 15 minutes the students are questioned. The staff member usually carries a brown bag that contains individual topics of the concept discussed in the class. Students are asked to pick a paper in random and explain about it as shown in figure 6 . This methodology will help students to understand the concept and reciprocate with ease and confidence. These techniques were applied on Linear IC applications, Electronics devices and circuits, switching theory and logic design.

IDEA: A brown bag is filled with papers having different topics of the subject written on them. Each student is asked to pick a paper of his/her choice. And they are given an opportunity to explain it.

IMPLEMENTATION: Suppose a faculty member teaches Applications of Linear Digital IC. The following topics are written on a white paper, and kept in brown bag. Students are asked to pick papers and explain them. Some of the topics written on a paper are

1. Inverting amplifier

2. Non inverting amplifier

3. Integrator

4. Differentiator

5. Difference amplifier

6. Instrumentation amplifier

EVALUATION: Students are requested to pick a paper and explain about the topic for a few minutes.

OUTCOME: This allows students to experience a real time exchange of knowledge with spontaneous response on topics dealt prior to the approach. This methodology will improve the quality of students as the answers are spontaneous, memory of the student increases and attentiveness in the class as well.

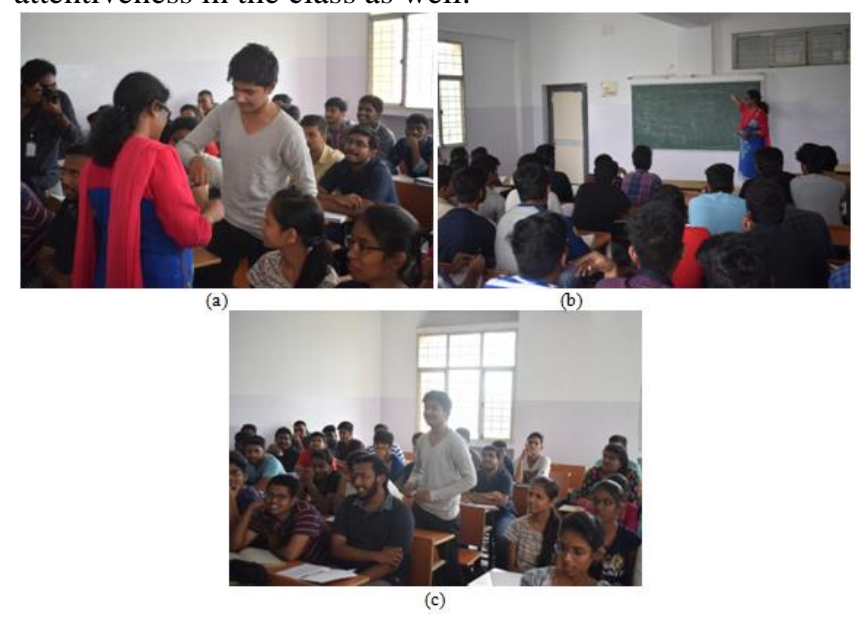

Figure 6 Snap shot indicating brownbag approach with students

G. Never miss a class (Proposed Innovative teaching methodology)

This is a novel innovative teaching methodology developed by Dr.K.Vasanth in the Department of ECE. It is used by the faculty of the department for the students who frequently are absent for subjects, which involves more problems. Generally, if a student is absent for the class he writes down the missed class notes without understanding. This instructional methodology will give a video of problems solved in the class, which the student has missed. Hence the student will never miss a class as the entire solved problem in the class is discussed in the form of a video. This gives the student a vivid idea about the concepts even if they miss the class. This method has been employed on difficult courses such as Signals and Systems and Digital signal processing for three successive years and experience and results were shared in this paper. The developed video is shared to students What's app( An app in mobile phone mostly used by students to broadcast messages) group. Figure 7 gives the screenshot of the video shared with the students. Figure 8 illustrates the video shared with students in what's app.

IDEA: Videos of topic of each class is prepared using a Pen tablet by the faculty members.

IMPLEMENTATION: These videos are posted on the students' Whats app group posed by the class.

EVALUATION \& OUTCOME: The clarity of the class is still intact with this video approach. Hence students understand the concepts well even after end of the course. This method helps students to score marks in their exams and choose this subject as area of interest during their placements.

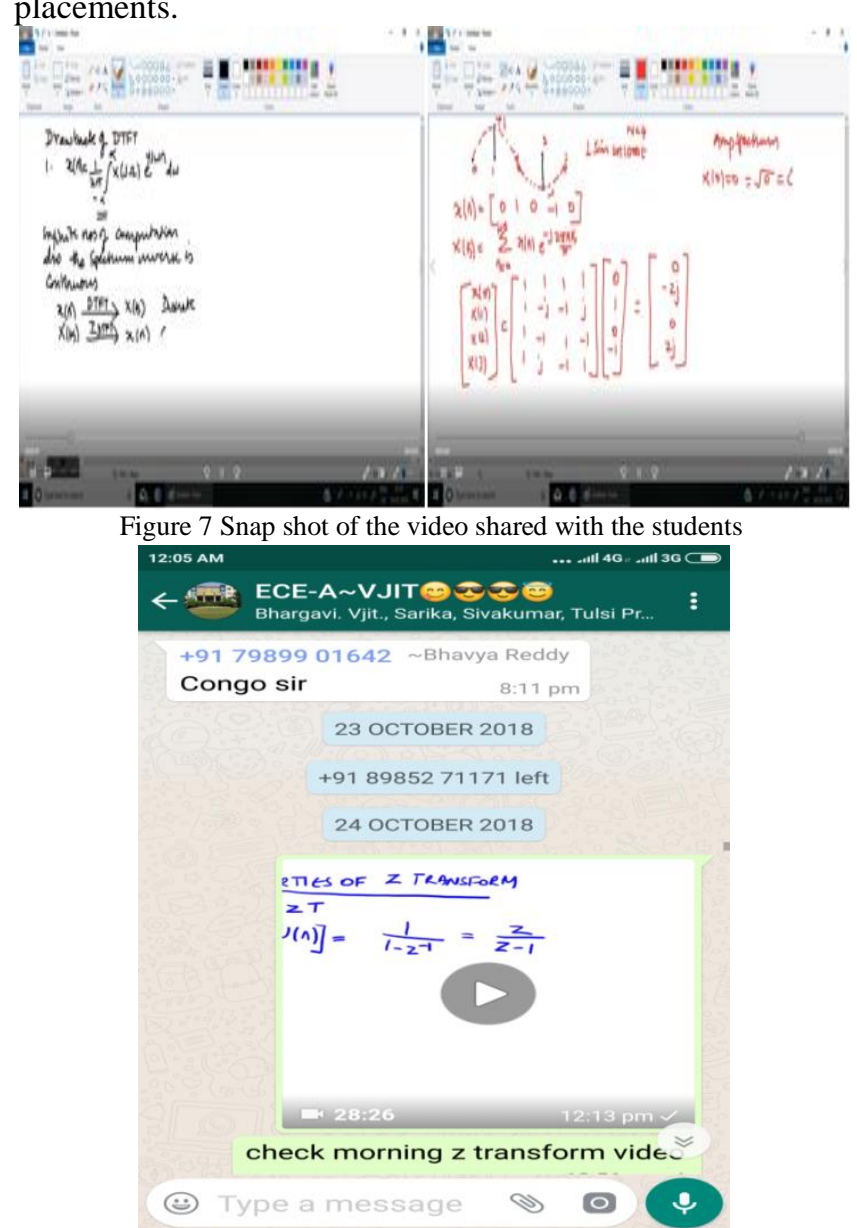

Figure 8 illustrates the video shared with students in what's app.

\section{Outcomes of Innovation}

The main objective of adopting these strategies is to make concepts clear for the students and make students reproduce during solving assignments, score during end exams and interview. Also these innovative methodologies will aid the conventional black board \& chalk method for enhanced learning. Considering a numerical based subject, 
the student neither attends class regularly nor knows how to solve the problems when it is required. Hence the technique called "Never Miss a Class" was introduced to solve the

Table 1 Percentage of students understands and retained the concepts after using innovative teaching methodology in the academic year 1819 for the course Digital signal processing

\begin{tabular}{|c|c|c|c|c|c|c|}
\hline S.No & $\begin{array}{c}\text { Name of the Innovative } \\
\text { teaching methodology }\end{array}$ & $\begin{array}{c}\text { Number of } \\
\text { Students } \\
\text { involved }\end{array}$ & $\begin{array}{c}\text { Number of } \\
\text { students } \\
\text { successfully } \\
\text { Answered }\end{array}$ & $\begin{array}{c}\text { Number of } \\
\text { students } \\
\text { successfully } \\
\text { Answered } \\
\text { after } \\
\text { fortnight }\end{array}$ & $\begin{array}{c}\text { \% of } \\
\text { students } \\
\text { understands } \\
\text { During the } \\
\text { class }\end{array}$ & $\begin{array}{c}\text { \% of } \\
\text { Students } \\
\text { understands } \\
\text { after a } \\
\text { fortnight }\end{array}$ \\
\hline 1 & Black Board chalk & 60 & 35 & 10 & 58.33 & 16.66 \\
\hline 2 & $\begin{array}{c}\text { Socio constructive } \\
\text { perspective }\end{array}$ & 60 & 40 & 22 & 66.66 & 36.66 \\
\hline 3 & Group projects & $60(15$ per & 47 & 27 & 78.33 & 45 \\
\hline 4 & batch) & 60 & 52 & 31 & 86.66 & 51.66 \\
\hline 5 & Dramatic role play & 60 & 57 & 35 & 95 & 58.33 \\
\hline 6 & Brown bag approach & 60 & 41 & 12 & 68.33 & 20 \\
\hline 7 & Never miss a class & 60 & 57 & 40 & 95 & 66.66 \\
\hline
\end{tabular}

\section{PERFORMANCE OF NEVER MISS A CLASS ( PROPOSED TEACHING METHODOLOGY) OVER OTHER METHODS - 2018-19 BATCH}

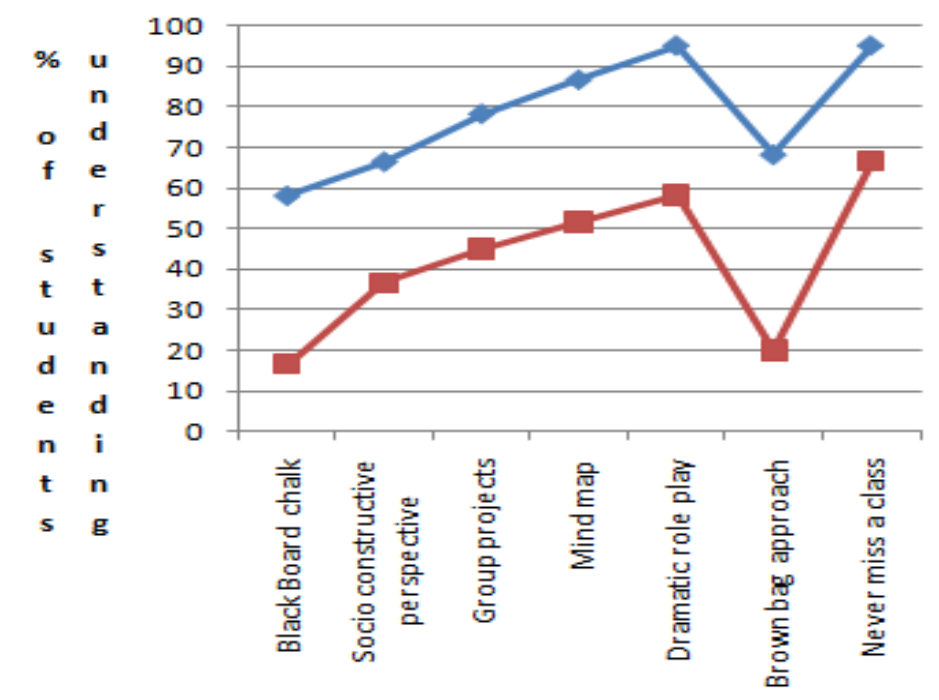

Figure 9 Comparison of different teaching methods on 2018-19 batch

Table 2 indicating the percentage of pass in Signals and Systems \& Digital signal processing

\begin{tabular}{|c|c|c|c|}
\hline S.No & Year & \% of pass in SS (II-I Sem) & \% of pass in DSP (III-II Sem) \\
\hline 1 & $\mathbf{2 0 1 6 - 1 7}$ & 58 & 69 \\
\hline 2 & $\mathbf{2 0 1 7 - 1 8}$ & 64 & 88 \\
\hline 3 & $\mathbf{2 0 1 8 - 1 9}$ & 69 & 91 \\
\hline
\end{tabular}

This methodology will develop affinity for the students as the subjects are in their interested format (i.e., videos). Hence the proposed methodology kindles the curiosity of the students and with "Never Miss a Class approach" offers a better experience in learning. The strategies adopted in the form of never miss a class has motivated students to learn difficult cum problematic subjects easily. This strategy paved a path for students to learn well and score good marks and retain the concept a little higher than the conventional method of teaching. It is found that the proposed teaching methodology helps the students to understand the concepts better and give exams in an easier way. The above discussed teaching methodologies are applied on three different batches of students from 2017 to 2019 for the courses such as signals \& systems (SS) and Digital signal processing (DSP) in Department of Electronics and Communication Engineering. 
Table 1 gives the Percentage of students who have understood and retained the concepts after using innovative teaching methodology for academic year 2018-19 for the course Digital signal Processing (DSP). The Outcome of the proposed teaching methodology is tested by conducting an experiment on a class of 60 students. The methodology of experiment is that a faculty member uses different teaching methodology for teaching a particular course (Numerical based subjects). The students are evaluated by questioning each student after each class employing different methods of teaching. The number of students successfully answered is noted. Now the same topic is given as part of assignment to students after a fortnight. It is found that the proposed teaching methodology was useful in retaining the concepts of the subject far more than other methods. This is evident that students used the video materials for solving the given assignment problems. The concept and problem solving methods stay fresh in the minds of students when they gaze through the videos.

It was found that the proposed method of teaching methodology was mostly used by students for solving assignments and score during end exams. The Percentage of students understands and retained the concepts after using Never Miss a Class (proposed teaching methodology) showed greater concept retaining ability and reproducibility. The concept retaining capability was found to have more impact on students. It was observed from table 1 that the percentage of students understanding the concept after a class was high for methods such as Mind Map, Dramatic Role play and Never miss a class (Proposed methodology). But the same set of students was tested after a fortnight with an assignment that consists of questions that was taught before. It was observed that the concept retaining ability and reproducibility of students were found to be higher in proposed teaching methodology (Never miss a class) when compared to other methods employed by the teacher as shown in figure 9.

The adoption of innovative teaching methodologies on problematic subjects such as Signals and systems, Digital signal Processing (DSP) had resulted in Ease of understanding subject, motivated to learn more, Acknowledgement given by students over the subjects and confidence to take up the subject as their area of interest during projects and placements. The same is reflected in the end exams too as shown in table 2. The students felt comfortable and felt easy to face exam because of the above innovative teaching methodology.

\section{Conclusion}

The main problem encountered while teaching the students of $2 \mathrm{~K}$ is that the students were unable to listen to conventional black board methods. A Novel Teaching methodology called "Never Miss a class" is proposed for students who were born after the year 2000. The proposed teaching methodology used video as a medium for broadcasting of lectures in students Whats app group. This method was adopted for numerical subjects. These students adhere more to videos and hence it was found that the students liked the methodology and used it while solving assignments. The methodology in which the problems are solved is in video lectures. This helps the students while solving assignments or preparing for external theory exams or placements or elsewhere. The proposed method was implemented for students taking up course such as signals and systems and Digital Signal Processing. The proposed methodology was a huge success with students because of its approach. It even gave the students a new dimension to learn the subjects along with conventional black board \& chalk method. The students' concept retaining ability was found to be good when compared to other methods used in class work. Also, the students of different batches performed better in their external exams. Hence the issue of retaining the concept and scoring marks during the end exams were achieved using this methodology.

\section{References}

[1] Michael Wald, " Trends in Engineering education ", (2007) IEEE Meeting the Growing Demand for Engineers and Their Educators 2010-2020 International Summit, 117,2007

[2] Schunk, D.(2012). Learning theories: An educational Perspective (6th Ed). (Pearson Education, Boston, MA)

[3] McMahon, M. (1997) Social Constructivism and the World Wide Web - A Paradigm for Learning. ASCILITE conference. Perth, Australia.

[4] Johnson, D.W., and Johnson, R.T., (2004) Cooperative Learning and Social Psychology: The Interrelationship Among Theory, Research, and Practice, Symposium: Efforts to Bridge Social Psychology and Education, Harris Cooper, Chair, Society of Experimental Social Psychology, Annual Conference, Dallas.

[5] DeVries, D., and Edwards, K., (1974) Learning Games and Student Teams: Their Effects on Classroom Processes, American Education Research Journal, Vol. 10, 1974,307318.

[6] Cohen, E., Designing (1986) Groupwork: Strategies for the Heterogeneous Classroom, New York, N.Y.: Teachers College Press.

[7] M. Rajendra Prasad, D. Krishna Reddy (2015), Project Based Teaching Methodology for Embedded Engineering Education, Journal of Engineering education and transformations, 1-6.

[8] Woods, D.R., (1994) Problem-Based Learning: How to Gain the Most from PBL, Waterdown, Ontario.

[9] Springer, L., Stanne, M.E., and Donovan, S. S.,(1999) Effect of Small Group Learning on Undergraduates in Science, Mathematics, Engineering and Technology: A Meta-Analysis, Review of Educational Research, Vol. 69, (1), 21-51.

[10] Dochy, F., Segers, M., Van den Bossche, P., and Gijbels, D.,(2003) Effects of Problem-Based Learning: A Meta-Analysis, Learning and Instruction, Vol. 13,533-568.

\section{Acknowledgement}

The author would like to thank the management of VJIT to render permission to perform the above exercise for better understanding ability of students pursuing Engineering education. 